\title{
Wastewater Treatment Prototype and Technology Development for Natural Resource and Environment Conservation using Community Based on Local Knowledge
}

\author{
Witthaya Mekhum
}

\begin{abstract}
This research was aimed to develop the prototype wastewater treatment technologies to conserve natural resources and environment of local community. The results revealed about the production problems and their impacts on the environment. The community houses had a massively impact on the environment and surrounding community that happened as follows. 1) The issue of chemical residues in water 2) The health issues were directly caused by conventional treatment processes. In addition, the results before and after the sewage were found as followings. (1) The $\mathrm{pH}$ before was 9.50 and after treatments of wastewater was 8.30. (2) BOD Before treatment with $110 \mathrm{mg} / \mathrm{L}$, and after wastewater was $17.60 \mathrm{mg} / \mathrm{L}$. (3) COD Before treatment with $629 \mathrm{mg} / \mathrm{L}$, and untreated sewage was $100.64 \mathrm{mg} / \mathrm{L}$. 4) Lead before treatment with the $0.32 \mathrm{mg} / \mathrm{L}$, and the untreated wastewater was $0.13 \mathrm{mg} / \mathrm{L}$. (5) Mercury before treatment with $0.0005 \mathrm{mg} / \mathrm{L}$, and the untreated wastewater was $0.0005 \mathrm{mg} / \mathrm{L}$.
\end{abstract}

Index Terms-Technology development, wastewater treatment prototype, natural resource and environment.

\section{INTRODUCTION}

Thailand, in the context of sustainable development that takes into account all aspects of a holistic, balanced on the basis of natural resources, traditional knowledge and culture of Thailand with the participation of all groups of people with generosity, mutual respect, the ability to self-reliance and quality of life equally as strategic environmental management plan 2012-2016, Environmental quality management plan 2012-2016, which consists of six strategies, which are 1) adjusting production and consumption to be environmentally-friendly, 2) conservation and restoration of natural resources sustainable, natural resource management and environmental, 3) in order to strengthen good governance, 4) creating a good environment for people to all levels, 5) preparation equipped to cope with the risks of change weather conditions and natural disasters, 6) Development and Social Responsibility and Environmental, Department of Environment Promotion (2010) conforms to creating a better environment for its citizens at all levels, which aims to prevent and reduce pollution at the source and decentralized management environment to manage effectively, creating a better environment for its citizens and to maintain the quality of the natural environment and the arts. The program featured three programs are 1) pollution management (water quality,

Manuscript received May 23, 2016; revised September 2, 2016.

Witthaya Mekhum is with the Faculty of Industrial Technology, Suan Sunandha Rajabhat University, Bangkok, Thailand (e-mail: witthaya.me@ssru.ac.th,mekhum@yahoo.com). air quality, solid waste and hazardous waste, community, and industry), 2) management of the urban environment and community green spaces and landscapes, and 3) environmental management of natural resources, the geology, and natural resources, arts and culture [1].

Here are the stained fabric is dyed easiest less expensive cost of color from natural or synthetic color was and dyeing finished a dye that makes clothing and exotic look up or change the original color of clothing or remove stains on the clothes better method is suitable for the occupation of the family in accordance with the "OTOP" is the one that will create prosperity for the community to enhance the well-being of the community as well. By producing or managing the resources available locally to become a quality product, this feature is consistent with the unique culture in local markets both at home and abroad. The basic principle three main local to global, self-reliance and building human resources [2], where quality control is very much needed to have the quality to produce the product is according to the standards, the facility is set [3], to consider the issue of wastewater quality in the production of garments and tied using local knowledge to build a wastewater treatment process in this area, there are many communities career the handicrafts, especially clothing, and tie-dye are grouped together making community. For making tie-dyed garments and today are encouraged to do this more regularly, but such production is a problem many ways. This makes the implementation of this type of business cannot develop as a serious environmental problem, which is clear that the root cause of the problems and solutions specific issues effluent from the production process. The color dyes used to color the chemical, which must find a way to treat wastewater occurred. The wastewater adversely affects the environment, the community, and the country, especially wastewater discharge directly into the public water supply is not treated properly chemical residues, which would be harmful to the aquatic environment due to jobs that need to be developed as tourist maintain or preserve a traditional way of life without a negative impact on the city is quiet, shady, environment, where there are plenty, but because the province is of interest to tourists who come to visit and what is going to happen as a result of the decline caused by the garbage and sewage from the activity occurred within the community and tourist accommodation. Generally, the waste will be how to deal with the plastic bag or trash to wait for the relevant authority hair removal and offsite disposal areas are some of the ways reclamation and burned. The water will drain into the public trough body and drained into canals or rivers, if the system is not well managed in such crashes will inevitably 
impact on the environment in the course.

Nowadays, Muang District, Nonthaburi province, a community of 57 products in the five star, 10 products, four star, 25 products, three star has 22 products, which the community is supported by the Office of Community Development, where the job promote employment of residents the conventional wisdom has been handed down and carried out a new promotion [4], by organizing professional training and coordination of short-term supply of products, which are the source of a great career that is the pride and bring revenue into the community in the area of Nonthaburi province, which is composed of many different types of crafts such as Thailand and garment dyed that held at the four star, which is the wisdom of the community inherited from ancestors can be exported to markets in the region Muang District, Nonthaburi province. There are many communities that employed the handicrafts, especially clothing and tie-dye are confederation president, is making the community Miss Wongdoen Platpoolpol be made garments and tie-dye, which currently has the support to do this more regularly, but such production is a problem many ways. This makes the implementation of this type of business cannot develop as a serious environmental problem. The problem is clear about the root cause of problems and solutions, particularly issues of wastewater from the production process. The color dyes used to color the chemical, which must find a way to treat wastewater occurred. The wastewater that adversely affect the environment, the community, and the country, especially the release of waste water into the public water supply has not been directly treated in the right way, the residual chemicals are harmful to the aquatic environment.

Product manufacturing dyeing cloth that historians assumed for Egypt because of the evidence from the clothes found in the ancient tomb. The remnant of those colors and patterns, however, it is also found in Asian countries like China and India. Ii doesn't have a clear opinion that people do as a starter. So if the story of the invention of synthetic dyes that occur after the 1st World War, the first by a German chemist. The Americans had invented and produced synthetic dyes as well as to the world, however, we know that human use of natural colors from plants like before the leaves, bark, roots, tubers or extracted for the cloth, which is dyed and began to prepare a clean white cloth how to tie a pretty tie is based on techniques and methods of zigzag patterns, which can affect the response to be out in a circular pattern, it must be pointed pleated fabric by folding truss that is pointed out and understood that we tied it is to be born white was to tie a cloth exhausted plots the next step of this is to remove the towel tied to the pot staining pattern beautiful on the textile dye. This story has many uses. The artistic beauty of nature combined with the creative wisdom of Thailand, we have tie-dyed fabric that can be sewn into clothes, bags or use a handkerchief. The professional garments and fabric dyed a career that preserves and promote the use of local knowledge produces craft of dyeing fabric type. This makes the eye-catching fabric buyer is one of the reasons that make the fabrics sold well, the fabric is dyed at just how good depends on choosing the correct dye on the type of fiber and dye method to perform the correct technique.

The omission of any shortcomings by the thought might not be necessary discolor or fall colors, spotted or fiber deteriorated. The characteristic staining dye has several phases together either before or after spinning, before or after the time knitting and dyeing the yarn [5]. But at this stage is to dye fabric. Dye is not the easiest color consumption cost of natural or synthetic dyes can be dyed and finished fabrics dyed clothing that makes it look more exotic or change the color of the clothes or the negative stain clothes better method is suitable for the occupation of their parents. Such behavior of the waste management and wastewater community to develop, however, to resolve such problems, the researchers then had the idea to develop a technology prototype wastewater to conserve natural resources and environment of the community based on local knowledge in Nonthaburi province, where the results of this research will be of benefit to the community with products that deliver results environmentally, therefore, there is no need to rush and be aware of the problem by using local knowledge to determine the effectiveness and guidelines for compliance with the guidelines for the management of waste and wastewater, community and conservation of traditional knowledge to promote cultural Tourism Community Nonthaburi descendants have inherited forever.

\section{OBJECTIVE}

To develop a wastewater prototype to conserve natural resources and environment of the local community based on local knowledge.

\section{METHODOLOGY}

\section{A. Scope of the Research}

The study area was used to collect data and create a prototype in the Meung District, Nonthaburi province, Thailand.

\section{B. Research Methodology}

This research is the sample garment manufacturers and fabric dye, which is a total of 15 cases of all the information. In this research used the wastewater test prototype to conserve natural resources and environment of the local community on the base the qualitative research and experimental. The instrument is divided into two processes comprising the first problems of production and its impact on the environment using in-depth interviews and group meetings at the two wastewater analysis before and after treatment by developing trial and build a prototype wastewater treatment community on the basis of local knowledge available.

\section{RESULTS AND ANALYSIS}

Consider the production problem and impact on the environment due to production houses, which are located in the communities of rural people living together intensively. Thus, the impact on the environment and community environment occurs. The houses of the population living in the community so massively impact on the environment and 
surrounding community that happens to occur as follows. (refer with: Fig. 1 and Fig. 2).

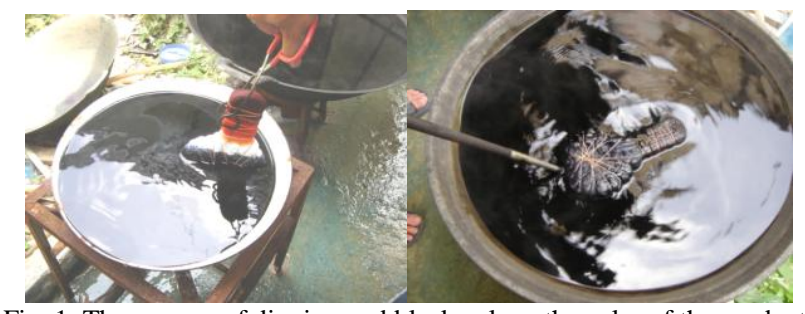

Fig. 1. The process of dipping and black colors, the color of the product.

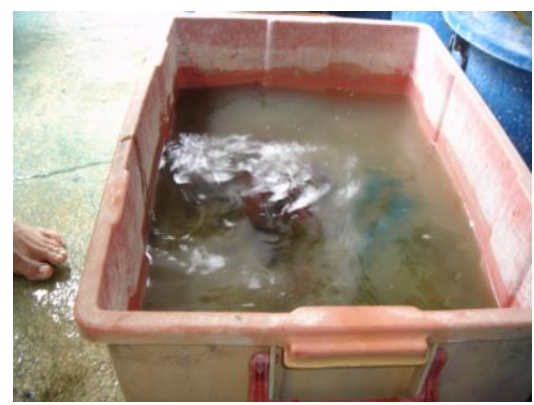

Fig. 2. Chlorine dip after dipping paint for 1- 3 minutes

The first chemical residues in water due to the production process that uses chemical dyes to dye fabric, of course, reject water cannot be treated with residue into a public course. The purpose of this research is to solve problems for the operators of sewage dumped into the stream from the production process before the public. The hot-air wastewater treatment and installed permanently (refer with: Fig. 3 and Fig. 4).

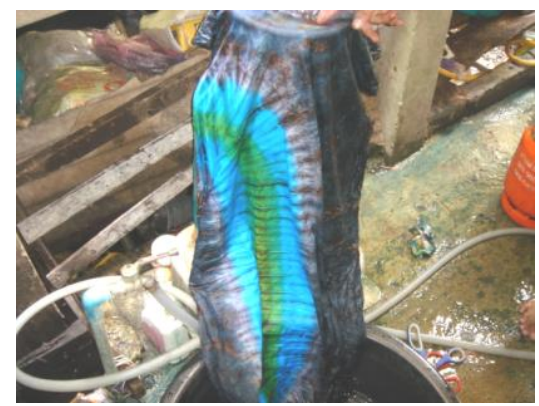

Fig. 3. The process of washing with water.

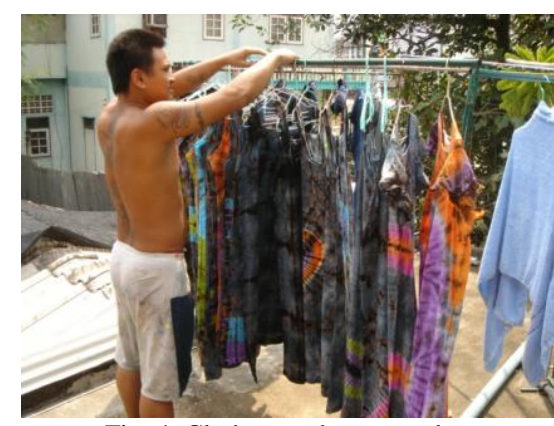

Fig. 4. Clothes on the sun to dry.

Two groups of health problems directly caused by conventional treatment processes, which requires the tangible substance to separate chlorine tank to precipitate and discarded or until the chemical or powder scoop sediment from the bottom of the tank, which poses a danger to those exposed, if not protected well enough.

Water Analysis Before and After Treatments (refer with: Table I)
TABLE I: THE COMPARISON OF WATER QUALITIES BEFORE AND AFTER TREATMENTS

\begin{tabular}{lcccc}
\hline \hline Quality index & Unit & $\begin{array}{c}\text { Sewerage } \\
\text { Standard }\end{array}$ & $\begin{array}{c}\text { Before } \\
\text { Treatment }\end{array}$ & $\begin{array}{c}\text { After } \\
\text { Treatment }\end{array}$ \\
\hline 1. $\mathrm{pH}$ & - & $5-9$ & 9.50 & 8.30 \\
2. BOD & $\mathrm{mg} / \mathrm{L}$ & $\leq 20$ & 110 & 17.60 \\
3. COD & $\mathrm{mg} / \mathrm{L}$ & $\leq 120$ & 629 & 100.64 \\
4. Lead & $\mathrm{mg} / \mathrm{L}$ & $\leq 0.20$ & 0.32 & 0.13 \\
5. Mercury & $\mathrm{mg} / \mathrm{L}$ & $\leq 0.005$ & 0.0005 & 0.0005 \\
\hline \hline
\end{tabular}

\section{CONCLUSION}

The results before and after the sewage were found as followings.

1) $\mathrm{pH}$ : before and after treatments were 9.50 and 8.30 , respectively.

2) BOD: before and after treatments were $110 \mathrm{mg} / \mathrm{L}$ and $17.60 \mathrm{mg} / \mathrm{L}$, respectively.

3) COD: before treatment with $629 \mathrm{mg} / \mathrm{L}$, where the untreated sewage was $100.64 \mathrm{mg} / \mathrm{L}$.

4) Lead: before treatment with the $0.32 \mathrm{mg} / \mathrm{L}$, where the untreated wastewater was $0.13 \mathrm{mg} / \mathrm{L}$.

5) Mercury: before treatment with $0.0005 \mathrm{mg} / \mathrm{L}$, where the untreated wastewater was $0.0005 \mathrm{mg} / \mathrm{L}$.

It can be seen that compared the quality of the effluent treatment system prior to the wastewater treatment system and then passed through a treatment designed. The treated water was found to have better water quality criteria based on the Ministry of Industry No. 2, 2539 feature set of wastewater discharge outside the plant. The analysis of water quality can be released into the environment without any environmental impact (refer with: Fig. 5).

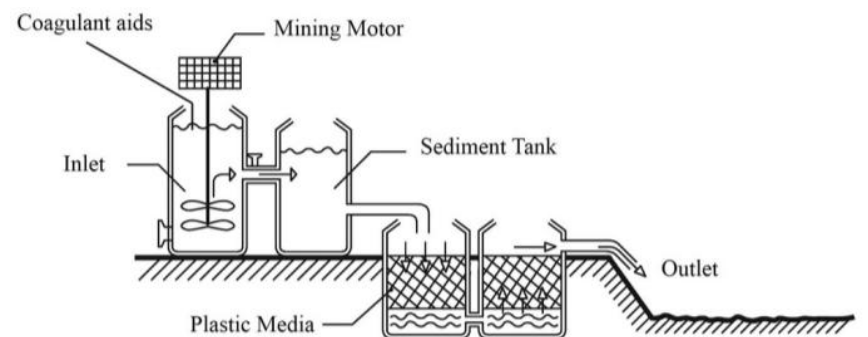

Fig. 5. Prototype wastewater treatment community on the basis of local knowledge.

\section{DISCUSSION}

The quality of the effluent treatment system prior to the wastewater treatment system and then passed through a treatment designed. The treated water was found to have better water quality criteria based on the Ministry of Industry No. 2 of 1996. defining the feature of effluent discharged outside the factory. The analysis of water quality that can be released into the environment without any environmental impact, water management system in the Bangbuathong area, Nonthaburi, Thailand finds solutions to restore water quality in the community and the authorities concerned can proceed by reducing the organic loading dirt into the canal that runs from the source is in the area. There should be a proper wastewater treatment systems, grease traps, biological 
wastewater treatment, air quality and for residents to install water treatment systems, stick with that is consisted of grease traps and septic anaerobic filter of the house and measures for living areas on two sides of the canal required the understanding of wastewater management through training, education and activities in the community together ongoing. The wastewater management system that needs to be implemented in three parts, which are (1) the right technology, (2) participation of the community and society, and (3) economics which is consistent with the research of Helen E.M and James R.M [6], for technology that relies on energy from natural or appropriate technology and local knowledge, it can be done in order to conserve natural resources and the environment.

\section{SUGGESTION}

The data from the research of waste from manufacturing, products, garments and textile dye wastewater, produced what happens is water, we must find a way to get rid of waste that occurs. The wastewater that adversely affect the environment and the local community, particularly the release of waste water into the public water supply directly, no way to treat a great impact on the ecological system and harmful things, other life, so it is essential to use technology to help in the treatment of waste water, which is used to treat wastewater anaerobically.

\section{ACKNOWLEDGMENT}

The author would like to thank the Research and
Development Institute, Suan Sunandha Rajabhat University, Bangkok, Thailand for financial support.

\section{REFERENCES}

[1] Department of Environment Promotion, "The development of waste management system participation: A case study of Banklang Sub-district Administration, Lamphun province," 2010.

[2] Department of Community Development, Ministry of Interior, Report on OTOP, Bangkok Department of Community Development, 2015.

[3] C. Tarasawatpipat et al., Development of the Production of Diesel Fuel from Waste, Bangkok: Environment Studies, Suan Sunandha Rajabhat University, 2015.

[4] T. Jiankul, "Problems and adapting to OTOP with the opening of the AEC," Hua Chiew University Journal, vol. 34, no. 1, 2014.

[5] S. Santipollawut et al., "Community enterprise development under the OTOP operators leverage potential towards SMEs," Bangkok: Research and Development Institute, Kasetsart University, 2012.

[6] H. E. Muga and J. R. Mihelcic, "Sustainability of wastewater treatment technologies," Sustainable Futures Institute, Michigan Technological University, Houghton Journal of Environmental Management, vol. 88, pp. 437-447, 2008.

Witthaya Mekhum was born on April 27, 1969 in Suan Sunandha Rajabhat University 1 U-Thong Nok Road, Dusit, Bangkok 10300, Thailand. Witthaya Mekhum received the doctor of philosophy (2007) (doctor of philosophy (technology management), from Phranakhon Rajabhat University); the master degree (2001) (master of science in technical education (technical education technology) from King Mongkut's University of Technology North Bangkok); the bachelor degree (1992) (bachelor of science program in industrial technology, Suan Sunandha Rajabhat Institute). Witthaya Mekhum is the vice president for Research and Development, Suan Sunandha Rajabhat University. 